\title{
Kernos
}

Revue internationale et pluridisciplinaire de religion grecque antique

$10 \mid 1997$

Varia

\section{J. LACROSSE, L'amour chez Plotin}

\section{André Motte}

\section{(2) OpenEdition}

\section{Journals}

\section{Édition électronique}

URL : http://journals.openedition.org/kernos/684

DOI : $10.4000 /$ kernos.684

ISSN : 2034-7871

Éditeur

Centre international d'étude de la religion grecque antique

Édition imprimée

Date de publication : 1 janvier 1997

Pagination : 348

ISSN : 0776-3824

Référence électronique

André Motte, « J. LACROSSE, L'amour chez Plotin », Kernos [En ligne], 10 | 1997, mis en ligne le 12 avril 2011, consulté le 23 septembre 2020. URL : http://journals.openedition.org/kernos/684 ; DOI : https:// doi.org/10.4000/kernos.684 
Cet ouvrage, qui enrichit de façon originale notre connaissance des Nuées, se termine par une bibliographie sélective, forte d'environ quatre-vingt titres.

André MOTTE

(Université de Liège)

Joachim Lacrosse, L'amour chez Plotin. Erôs hénologique, Erôs noétique, Erôs psychique, Bruxelles, Éditions Ousia, 1994. 1 vol. $14 \times 21 \mathrm{~cm}$, 143 p. (Cabiers de pbilosopbie ancienne). ISBN : 2-87060-044-5.

Il existait déjà, sur la figure d'Éros chez Plotin, une littérature assez abondante, mais on se réjouira de voir ici le thème exploré d'une façon systématique qui permet à la fois d'en aborder les multiples facettes et de les replacer ensuite dans une perspective globale. La première partie est opportunément consacrée à l'exégèse des données platoniciennes exploitées par le lointain disciple; continuités et ruptures y sont bien mises en évidence, ce qui constitue une excellente introduction aux différents thèmes plotiniens examinés dans la suite. Dans le second chapitre, l'érôs est étudié dans ses rapports avec la conversion de l'âme et avec celle du Nô̂s vers l'Un; l'occasion se présente ici d'aborder la démonologie de Plotin, - Érôs est identifié au « Grand Démon »-, et sa morale sexuelle. Le dernier chapitre examine un aspect moins connu du thème, bien que le plus original et le plus fondamental, celui de l'Érôs hénologique, l'amour de soi par lequel l'Un engendre, sans en être altéré, les réalités issues de lui. C'est ici que l'on perçoit notamment combien l'érôs et le logos sont très étroitement associés. Une synthèse éclairante est fournie dans la conclusion justement intitulée «L'omniprésence de l'amour ». Importante bibliographie.

André MOTTE

(Université de Liège)

Marie-Madeleine Mactoux, Evelyne GeNy (éds), Discours religieux dans l'Antiquité. Actes du colloque (Besançon, 27-28 janvier 1995), Paris, Les Belles Lettres, 1995. 1 vol. 15,5 ×24 cm, 322 p. (Annales littéraires de l'Université de Besançon, 578. Centre de Recherches d'Histoire ancienne, 150). ISBN : 2-251-60578-9.

Les 15 communications que reproduisent ces Actes couvrent une vaste période qui va d'Hésiode à Vincent de Lérins, un auteur chrétien du $v^{\mathrm{e}}$ siècle, et la thématique abordée, tant en ce qui concerne les types de discours religieux pris en compte que les analyses auxquelles on les soumet, présente à son tour une grande diversité. Aussi n'est-il pas inutile de prendre d'abord connaissance de l'avant-propos synthétique, dû à M.-M. MACTouX, avant d'entamer la lecture de l'ouvrage; y sont notamment présentées les trois pistes de réflexion qui ont servi à regrouper les interventions. La première est centrée sur les « destinataires et la réception des discours religieux inscrits dans les discours eux-mêmes sous diverses modalités ». Une contribution de Cl. CALAME (Invocations et commentaires "orpbiques": transpositions funéraires de discours religieux) ouvre cette série; riche d'érudition et d'observations minutieuses, mais d'une lecture difficile, elle confronte, dans leurs fonctions énonciative et performative, deux types de discours "mystiques " et à usage funéraire, le papyrus de Dervéni et les deux lamelles d'or récemment découvertes à Pélinna. J.-M. PAILler 